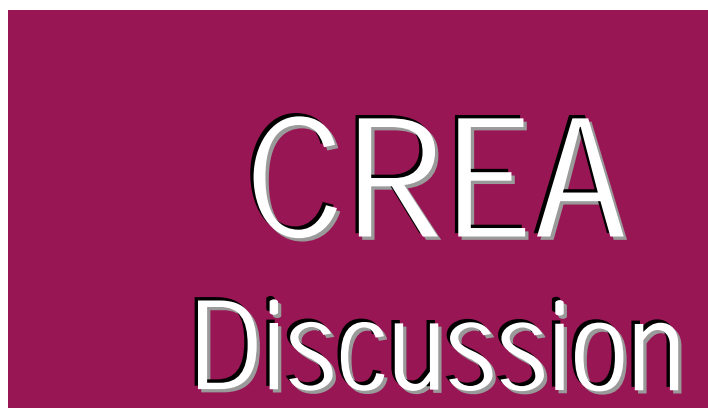
Paper

\title{
2014-05
}

Center for Research in Economic Analysis

University of Luxembourg

\section{On the impact of competition on trade and firm location}

available online : http://wwwfr.uni.Iu/recherche/fdef/crea/publications2/discussion_papers

Toshihiro Okubo, Keio University, Tokyo, Japan

Pierre Picard, CREA, Université du Luxembourg

Jacques-François Thisse, CORE, Université catholique de Louvain, Belgique

December, 2013

For editorial correspondence, please contact: crea@uni.lu

University of Luxembourg

Faculty of Law, Economics and Finance

162A, avenue de la Faïencerie

L-1511 Luxembourg 


\title{
On the impact of competition on trade and firm location*
}

\author{
Toshihiro Okubo ${ }^{\dagger} \quad$ Pierre M. Picard ${ }^{\ddagger} \quad$ Jacques-François Thisse $^{\S}$
}

December 312013

\begin{abstract}
We study how the level of trade costs and the intensity of competition interact to explain the nature and intensity of trade within a given industry and the location of firms across countries. As trade costs decrease from very high to very low values, the global economy moves from autarky to two-way trade, through one-way trade from the larger to the smaller region. By exploring the intensive and extensive margins of exports, we investigate how the intensity of trade reacts to the degree of competitiveness. Furthermore, when firms are free to change location, they flow from the small to the large country, and the larger country is always a net exported on the manufactured good. Firms located in the big country have a bigger size than those located in the small one. Under one-way trade, the relocation of firms changes their attitude toward export.
\end{abstract}

Keywords: trade, competition, firm location, capital mobility

JEL Classification: F12, H22, H87, R12

${ }^{*}$ We thank the editor and two referees for very useful comments and suggestions.

${ }^{\dagger}$ Keio University. 2-15-45 Mita Minato-ku Tokyo, Japan. Email: okubo@econ.keio.ac.jp

${ }^{\ddagger}$ CREA, University of Luxembourg (Luxembourg) and CORE, Université catholique de Louvain (Belgium).

E-mail: pierre.picard@uni.lu

${ }^{\S}$ CORE, Université catholique de Louvain (Belgium), Université du Luxembourg, and CEPR. E-mail: jacques.thisse@uclouvain.be

IWe thank P. Conconi, F. Mayneris, H. Vandenbussche, and seminar participants at Keio University for helpful comments. This project has been supported by the grant F2R-CRE-PUL-10EGQH at the University of Luxembourg. 


\section{Introduction}

The new economic geography and trade literature has stressed the importance of trade barriers for the intensity of competition and the spatial pattern of the global economy. Somewhat surprisingly, much less attention has been paid to the reverse relationship: the impact of competition on the nature and intensity of trade as well as on the location of economic activities. Yet, one of the main lessons from the industrial organization literature is that the way domestic markets operate may facilitate or deter the entry of new, i.e. foreign, products. Furthermore, once it is recognized that the intensity of competition in domestic markets matters for trade, it should be clear that the way capital is distributed between countries should also affect trade through the difference in countries' competitiveness as determined by the number of domestic competitors. In this paper, we argue that such neglect is unwarranted. A reason for this is likely to be that the trade and new economic geography literature is dominated by the CES model of monopolistic competition in which equilibrium prices and outputs are independent of the number of firms. Furthermore, since demands are always positive, the trade pattern always involves two-way trade.

Specifically, we aim to study the joint impact of trade costs and competitiveness on the nature of trade, but also on the location of firms across space. By allowing capital to move between asymmetric countries, we are also able to endogenize the degree of competitiveness characterizing each country, and thus to determine the nature and intensity of trade as well as the location of firms in terms of market size and competitiveness. To achieve our goal, we use the linear model of monopolistic competition, which captures the following two basic features: competition gets tougher when the number of varieties increases as well as when the level of trade costs falls (Ottaviano and Thisse, 2004). We then combine this model with a two-asymmetric country setting to capture the well-documented fact that market size plays a major role in trade and location.

Commodity flows in world trade display a high degree of diversity. According to Helpman et al. (2008), two-way, one-way and no trade at all respectively account for 30-40, 10-20 and 50 - 60 percent of country pairs in 158 countries from 1970 to 1997 . We suggest a rational for such a diversity in trade regimes that differs from the role of fixed costs to export (Helpman et al., 2008), the disaggregation level of trade data (Baldwin and Harrigan, 2011) and, recently, additive trade costs (Irarrazabal et al., 2013). More precisely, we show how competitiveness and trade costs interact to explain trade regimes, ranging from autarky to two-way trade through one-way trade. In the one-way trade regime, the country producing the larger number of varieties exports toward the country having the smaller number of varieties because competition is softer 
therein. In other words, even though firms have the same productivity, their ability to export depends on the intensity of competition on foreign markets. This is to be contrasted with Helpman et al. (2004, 2008) where the choice to export is determined by firms' idiosyncratic productivity and fixed costs of serving foreign countries. The modelling of firm heterogeneity is needed in a setting that grasps the intensity of competition only through the level of trade costs. Although we acknowledge the importance of firms' heterogeneity, we offer an additional explanation for the existence of no trade, one-way or two-way trade, which encompasses the market-specific degree of competitiveness.

The measurement of competitive pressure is known to be a difficult task with no single approach. Our setting allows us to parametrize the intensity of competition through a single parameter that encompasses the number of firms and the degree of substitutability across the varieties available on domestic markets. By studying the intensive and extensive margins of export, we show that the intensity, and even the likelihood, of trade typically decreases as the market gets more competitive. This is because the penetration of foreign varieties becomes more difficult once the number of domestic varieties is large enough. As a consequence, the emergence of two-way trade within various sectors should not necessarily be interpreted as evidence of intensified competition and trade opening policies, as it is done by many policy studies. As shown in this paper, two-way trade occurs when competition among domestic varieties is weak. In contrast, a stronger degree of competitiveness fosters the emergence of one-way trade where only the large countries export. To put it bluntly, by making harder the penetration of foreign products, any policy facilitating the launching of domestic varieties mimics protectionism. This echoes Weinstein (1992) who showed that there is no room for imports when the price drop generated by entry in a single country is strong enough. Conversely, Melitz and Ottaviano (2008) observed that trade liberalization may deter the entry of domestic varieties. ${ }^{1}$

Since the international-interregional distribution of firms is a major determinant of the nature and intensity of trade, we find it natural to ask how capital is allocated when it is free to move from one country to the other. Such a footloose capital setup allows us to tackle an important issue about exports and competitive pressures: by changing their investment locations, capital-owners affect the intensity of competition within each country, thus making the penetration of foreign products easier or more difficult. In other words, how competitive are the local markets has an impact on the intensity of global competition, and vice versa. In particular, even though they share the same technology, firms that change location may change their attitudes toward export. For example, under one-way trade, the firms that choose to move

\footnotetext{
${ }^{1}$ Chen et al. (2010) provide some evidence supporting that idea.
} 
their production from the smaller to the larger country begin exporting because they are able to export in the smaller and less competitive market. As a consequence, the intensity of local competition and of trade changes via the location of firms.

This paper presents a footloose capital model developed by Ottaviano and Thisse (2004) in the spirit of Martin and Rogers (1995). It complements this work by offering an extensive discussion about the changes in aggregate exports and intensive and extensive margins of trade. Moreover, by assuming quadratic preferences for consumers, our model leads to a system of linear demands that encompass pro-competitive effects and finite, but endogenous, choke prices. These two features make it especially suitable to discuss the relationships between the intensity of competition and the nature of trade in new economic geography models. Our paper builds on Behrens' (2004, 2005a, 2005b) who first showed how competition effects may prevent firms located in small countries from exporting to large countries and endogenously create asymmetries in trade patterns. Although we offer a similar discussion about the relationship between firms' location and the existence of trade flows (Section 3), we present a more detailed and systematic analysis of the levels and determinants of trade flows. Our model does not only consider the international-interregional allocation of capital but also provides a full characterization of long run equilibria with the possibility of trade in one or two directions or no trade at all. In this paper we are able to discuss the set of economic parameters under which each trade direction is admissible, in particular, the case of trade of manufacturing goods in one direction. In addition to this, our paper discusses the impact of trade cost and intensity of competition on aggregate exports and trade margins through the relocation of firms. However, unlike Behrens (2004, 2005a), we do not study interregional migration of workers and the related demand linkages, which lead to agglomeration processes and narrow down the effects of trade opening. Last, like in most two-sector footloose capital models, bilateral flows in the tradable good need not be balanced. In our setting, the numéraire is transferred from the net importing country to equilibrate the trade balance.

Related literature. This paper merges several existing analyses. It revisits the consumer program in the presence of non-consumed goods (Behrens, 2004) and the short run analysis of one-way trade (Behrens, 2005a). It includes the location equilibrium under no trade (Behrens, $2005 \mathrm{~b}$ ) and the analysis of two-way trade (Ottaviano and Thisse, 2004). In contrast to Behrens (2004, 2005b) and Ottaviano et al. (2002), it does not consider the mobility of workers and, therefore, does not study the impact of demand linkages that belongs to the core-periphery model. The first contribution of the paper is to offer the full picture of all configurations with two-way, one-way and no trade within a unified framework. To the best of our knowledge, this reconciliation of the above-mentioned papers is novel. Beyond this, the paper offers additional 
findings that pertains to the presence of pro-competitive effects, which are stressed in the paper:

(i) the role of competition intensity in the firms' export decision and in trade flows and values;

(ii) the role of international capital location in the firms' export decision; (iii) the relationships linking local and global competition and firms' locations.

The remaining of the paper proceeds as follows. The next section introduces the model and characterizes the demand structure under autarky, one-way and two-way trade. Section 3 explores the product market equilibrium under these various trade regimes when capital and firms are immobile. Section 4 discuss the economy under capital and firm mobility when capital-owners invest in the country with the higher capital return. Section 5 concludes.

\section{The model}

The economy involves two goods - a tradable good and the numéraire - one production factor capital - and two countries-regions $i=H, F$ with a population of size $\theta_{H}$ and $\theta_{F}$, respectively; without loss of generality, we assume that $\theta_{H} \geq \theta_{F}$ with $\theta_{H}+\theta_{F}=1$. The global supply of capital is normalized to 1 . Individuals are endowed with some share of capital. ${ }^{2}$ They are immobile but free to invest their capital wherever they want and seek the highest rental rate.

The tradable good is defined by a continuum of horizontally differentiated varieties indexed by $k$. Each variety is produced by a single firm under increasing returns and monopolistic competition and each firm produces a single variety. To operate, a firm needs $f$ units of capital so that the total number of varieties produced in the economy is equal to $N=1 / f$. A larger value of $N$ means that either more capital is allocated to the sector under consideration, the launching of a firm needs less capital due to process innovations, or both. Note that labor and wages can be ignored because they have no impact on our results as preferences are quasi-linear. Last, shipping one unit of the tradable good between the two countries requires $t>0$ units of the numéraire. As for the homogeneous good, it is unproduced and freely traded. This good is chosen as the numéraire.

Turning to preferences towards differentiated varieties, we should stress that a key-feature of the model is that consumers may be unwilling to purchase all varieties. So, we need to distinguish the varieties that are available to consumers from those that are actually purchased by them. Yet, for the time being it is convenient to write preferences when the total number of varieties that are at consumers' disposal is equal to $N$.

\footnotetext{
${ }^{2}$ In this model, the distribution of capital ownership has no impact on the market outcome because of the quasi-linear preferences assumption made below.
} 
The utility derived from consuming $q_{k}$ units of variety $k \in[0, N]$ is given by

$$
u\left(q_{k}\right)=\alpha q_{k}-\frac{\beta}{2} q_{k}^{2}-\frac{\gamma}{2} q_{k} \int_{0}^{N} q_{l} \mathrm{~d} l .
$$

Thus, the marginal utility of variety $k$ decreases with its own consumption as well as with the total consumption of the tradable good. Preferences are obtained by nesting the subutility (1) into a linear utility. For any given price profile of varieties, a consumer chooses the quantity profile of the tradable good $\left(q_{k \leq N}\right)$ and the consumption $q_{0}$ of the numéraire, which maximize her utility

$$
U\left(q_{0}, q_{k \leq N}\right)=\alpha \int_{0}^{N} q_{k} \mathrm{~d} k-\frac{\beta}{2} \int_{0}^{N} q_{k}^{2} \mathrm{~d} k-\frac{\gamma}{2} \int_{0}^{N} q_{k}\left(\int_{0}^{N} q_{l} \mathrm{~d} l\right) \mathrm{d} k+q_{0}
$$

subject to the budget constraint

$$
\int_{0}^{N} p_{k} q_{k} \mathrm{~d} k+q_{0}=r+\bar{q}_{0}
$$

and to the nonnegative consumption constraints

$$
q_{k} \geq 0
$$

where $r$ is the rental rate of capital that will be endogenized in Section 4. The initial endowment of the numéraire, $\bar{q}_{0}$, is supposed to be large enough for this good to be consumed in equilibrium. The parameters $\alpha, \beta$ and $\gamma$ are interpreted as follows: $\alpha>0$ measures the desirability of the tradable good with respect to the numéraire; $\gamma>0$ is the degree of substitutability between variety $k$ and any other variety, whence a higher $\gamma$ means that varieties are less differentiated. The parameter $\beta$ measures the intensity of love for variety. Indeed, when a individual consumes a total quantity $Q$ of the tradable good and uniformly spreads this quantity over the $N$ varieties, she gets a utility equal to

$$
U\left(q_{0}, q_{k \leq N}\right)=\alpha Q-\frac{\beta}{2 m} Q^{2}-\frac{\gamma}{2} Q^{2}+q_{0}
$$

which is increasing in $N$. Hence, when the parameter $\beta$ rises, the consumer benefits more from spreading her consumption over the varieties. ${ }^{3}$ Without loss of generality, the unit of the numéraire is chosen for $\alpha=1$ and the unit of the tradable good for $\beta=1$ to hold.

Consumers do not necessarily purchase all varieties at their disposal at the prevailing prices. Let $N_{i} \leq N$ denote the number of varieties that are actually purchased and consumed in country $i$. As a consequence, $N_{i}$ is equal to $N$ when all varieties are consumed and is smaller than $N$

\footnotetext{
${ }^{3}$ Thus, $1 / \beta$ is the counterpart of the elasticity of substitution in the CES model of monopolistic competition.
} 
when some varieties are not consumed. As will be shown below, trade costs will inflate the price of imported varieties and could make them too expensive to be consumed in equilibrium. To determine $N_{i}$, we rank the $N$ varieties by increasing price order: $k<l \Leftrightarrow p_{i k} \leq p_{i l}$. The following proposition is proven in Appendix 1.

Proposition 1 There exists a cut-off variety $N_{i} \leq N$ and a corresponding cut-off price $p_{i}\left(N_{i}\right)$ such that consumers purchase all the varieties that have a price below $p_{i}\left(N_{i}\right)$. The demand for each variety $k$ is given by

$$
q_{i k}=\left\{\begin{array}{cc}
\frac{1}{1+\gamma N_{i}}-p_{i k}+\frac{\gamma}{1+\gamma N_{i}} \int_{0}^{N_{i}} p_{i l} \mathrm{~d} l & \text { if } k<N_{i} \\
0 & \text { otherwise }
\end{array}\right.
$$

while the cut-off variety solves the fixed point equation

$$
p_{i k}\left(N_{i}\right)\left(1+\gamma N_{i}\right)=1+\gamma \int_{0}^{N_{i}} p_{i l} \mathrm{~d} l .
$$

The cut-off price is smaller than one.

Quite naturally, consumers purchase only the varieties that are not too expensive. It is important to note that whereas too expensive varieties remain at consumers' disposal they do not affect the demand for the less expensive varieties that are actually purchased. Indeed, the cut-off variety and cut-off price are defined as the fixed point of (4), which depends only on the prices of the varieties that are actually purchased (i.e. $l \in\left[0, N_{i}\right]$ ). By the same token, the demand function of each purchased variety depends only upon the prices of varieties that are purchased by the consumer. This contrasts with standard analyses based on the CES in which all varieties are purchased. ${ }^{4}$

A variety $k$ is consumed in country $i$ if and only if $q_{i k}>0$, or equivalently if,

$$
p_{i k}\left(1+\gamma N_{i}\right)<1+\gamma \int_{0}^{N_{i}} p_{i l} \mathrm{~d} l .
$$

A consumer's demand is

$$
q_{i k}=\frac{1}{1+\gamma N_{i}}-p_{i k}+\frac{\gamma}{1+\gamma N_{i}} P_{i}
$$

where

$$
P_{i} \equiv \int_{0}^{N_{i}} p_{i l} \mathrm{~d} l
$$

is the price index, which includes only the varieties that are actually purchased in country $i$.

In the next section we turn to the study of trade in an equilibrium where firms are immobile. The choice of investment location will be investigated in the subsequent section.

\footnotetext{
${ }^{4}$ The above proposition also differs from Behrens' (2005a, p. 475) because demands do not include any "consumer reservation prices" for the goods that are not purchased.
} 


\section{Trade patterns}

In this section, we show how firms set their prices and discuss how competition and market integration affect trade patterns when firms are immobile.

\subsection{Firms' prices and export decisions}

For convenience, we focus on country $i$. We first consider the price decision of a domestic firm in market $i$ and then discuss the price and export decision of a foreign firm that exports from country $j$ to country $i$. Because domestic (foreign) firms are symmetric, they sell their varieties at the same price $p_{i i}\left(p_{j i}\right)$. Each firm being negligible to the market, it chooses its prices and its export status taking the price indices $\left(P_{i}\right.$ and $\left.P_{j}\right)$ as parameters.

A domestic firm producing in country $i$ chooses its price to maximize its domestic operating profits given by $\pi_{i i}=\theta_{i} q_{i i} p_{i i}$. Because marginal costs are zero, domestic producers make positive profits on domestic sales and always supply their domestic market. The first-order condition for profit maximization shows that the equilibrium consumption of a domestic variety is given by

$$
q_{i i}=p_{i i}
$$

It follows from (6) that all firms in country $i$ set the same profit-maximizing price given by

$$
p_{i i}=\frac{1}{2} \frac{1+\gamma P_{i}}{1+\gamma N_{i}}
$$

A foreign firm exporting to country $i$ chooses $p_{j i}$ to maximize its operating profit earned abroad, $\pi_{j i}=\theta_{i} q_{j i}\left(p_{j i}-t\right)$, where $t$ is the unit trade cost paid in the numéraire. Note that the firm produces only if it faces a positive demand: $q_{j i}>0$. More precisely, the firm exports if and only if it can set a low enough price to satisfy the condition (5). Their profit-maximizing condition yields

$$
q_{j i}=p_{j i}-t
$$

Because foreign firms are symmetric, the unconstrained price and export levels are the same across all foreign firms and given by

$$
p_{j i}=p_{i i}+\frac{t}{2}
$$

At this price, the consumption of a foreign variety is such that $q_{j i}=p_{i i}-t / 2$, which can be computed as follows:

$$
q_{j i}=\frac{1}{2} \frac{1-t+\gamma P_{i}-t \gamma N_{i}}{1+\gamma N_{i}}
$$


By (5), foreign varieties are exported to country $i\left(q_{j i}>0\right)$ if and only if the following export condition holds:

$$
t<\frac{1+\gamma P_{i}}{1+\gamma N_{i}}
$$

When this condition does not hold, those varieties are not exported $\left(q_{j i}=0\right)$.

\subsection{Trade patterns and trade flows}

Let $\lambda_{i}$ be the share of firms in country $i$, which we treat as exogenous in this section. Because each firm produces a single variety, $\lambda_{i}$ is also the share of varieties produced in country $i$. Let $\mu_{j} \in\left[0, \lambda_{j}\right]$ be the share of varieties imported from country $j$. Using those definitions, the number of varieties purchased in country $i$ is given by the sum of domestic and imported varieties: $N_{i}=\left(\lambda_{i}+\mu_{j}\right) N$.

In what follows, we first discuss the nature of trade patterns and, then, the intensity of trade flows.

Trade patterns The corresponding price index is

$$
P_{i}=\left(\lambda_{i} p_{i i}+\mu_{j} p_{j i}\right) N
$$

Since $p_{j i}=p_{i i}+t / 2$, the price index is a function of the domestic price $p_{i i}$ and the trade costs $t$. The market equilibrium price is determined by the fixed point condition $p_{i i}\left(P_{i}(x)\right)=x$, which implies that the equilibrium domestic price and price index are as follows:

$$
p_{i i}^{*}=\frac{1}{2} \frac{2+t \mu_{j} \gamma N}{2+\gamma N_{i}} \quad \text { and } \quad P_{i}^{*}=\frac{N_{i}+t \mu_{j} N\left(1+\gamma N_{i}\right)}{2+\gamma N_{i}}
$$

so that the export price is again

$$
p_{j i}^{*}=p_{i i}^{*}+\frac{t}{2} .
$$

Therefore, two export regimes may arise according to whether or not foreign varieties are imported at the equilibrium $\left(\mu_{j}=0\right.$ or $\left.\mu_{j}=\lambda_{j}\right)$. The export regimes are determined by the value of trade costs.

To stress the role of competition, we set

$$
n \equiv \gamma N
$$

which we call the competitiveness index of the global economy. ${ }^{5}$ The larger the number of

\footnotetext{
${ }^{5}$ Bresnahan and Reiss (1991) find substantial differences in the intensity of competition across professions and sectors.
} 
varieties and/or the lower the degree of product differentiation across varieties, the more competitive the global economy. Using $n$, we can define the trade cost threshold as follows:

$$
\bar{t}\left(\lambda_{i}\right) \equiv \frac{2}{2+\lambda_{i} n}<1
$$

which makes the export condition (8) binding when all foreign varieties are imported $\left(\mu_{j}=\lambda_{j}\right)$. This threshold falls with larger $\lambda_{i}$ and $n$ because local competition is tougher. As already noted by Behrens (2005a), market conditions and the degree of competition in foreign countries determine when exporting is, or is not, possible.

We show in Appendix 2 that all foreign firms (no foreign firms) export to country $i$ if $t<\bar{t}\left(\lambda_{i}\right)\left(t>\bar{t}\left(\lambda_{i}\right)\right) .{ }^{6}$ In other words, $q_{j i}^{*}>0$ and $\mu_{j}=\lambda_{j}$ when $t<\bar{t}\left(\lambda_{i}\right)$, whereas $q_{j i}^{*}=0$ and $\mu_{j}=0$ when $t>\bar{t}\left(\lambda_{i}\right)$. As a result, domestic consumers buy all foreign varieties when trade costs are low and/or the share of domestic competitors $\lambda_{i}$ is sufficiently small for competition in country $i$ to be soft. Conversely, foreign firms are unable to export when trade costs are high and/or the share of domestic varieties is large enough. This is because competition in country $i$ is too tough for foreign varieties to penetrate this market.

Finally, when the manufactured good becomes homogeneous $(\gamma \rightarrow \infty$ and thus $n \rightarrow \infty)$, the equilibrium domestic prices converge toward marginal cost (here zero) while trade vanishes because $\bar{t}\left(\lambda_{i}\right)=0$. Likewise, a smaller requirement $f$ of capital due to a technological improvement leads to a larger number of available varieties $N$, hence a larger $n$, which lowers prices and trade flows.

When there is trade from $j$ to $i$, a country $j$-firm supplies the quantity

$$
q_{j i}^{*}\left(\lambda_{i}\right)=\frac{2-(n+2) t+\left(1-\lambda_{i}\right) n t}{2(n+2)}
$$

to each country $i$-consumer. Thus, each firm's export decreases with the level of trade costs $t$ because $\mathrm{d} q_{j i}^{*} / \mathrm{d} t$ is proportional to $-(n+2)+\left(1-\lambda_{i}\right) n<0$. It also falls with the competitiveness index $n$ because $\mathrm{d} q_{j i}^{*} / \mathrm{d} n$ has the same sign as $\left(1-\lambda_{i}\right) t-1$, which is negative when $t<\bar{t}\left(\lambda_{j}\right)$, i.e. when the variety is exported from country $j$. It then follows from $(7)$ that the equilibrium price is given by

$$
p_{j i}^{*}=\frac{2+(n+2) t+\left(1-\lambda_{i}\right) n t}{2(n+2)}
$$

which decrease with a fall in $t$ because competition in country $i$ gets tougher.

To sum up, if varieties are close substitutes, domestic competition is tough and firms set their prices close to their marginal cost. Because they have no exogenous comparative advantage,

\footnotetext{
${ }^{6}$ We disregard here the zero-measure case $t=\bar{t}\left(\lambda_{i}\right)$ in which some indeterminate number of foreign firms export to country $i$.
} 
foreign firms are unable to export at a price exceeding their own local marginal cost plus trade cost. Thus, more competition, i.e. a higher $n$, need not foster trade. Conversely, if varieties are poor substitutes, two-way trade occurs because competition among domestic varieties is soft. In this case, two-way trade cannot be interpreted as evidence of intense competition and effective open trade policies.

Using the foregoing developments, the equilibrium trade pattern may be described as follows.

Proposition 2 Assume that the allocation of capital is fixed. Then, there is two-way trade if $t<\min \left\{\bar{t}\left(\lambda_{i}\right), \bar{t}\left(\lambda_{j}\right)\right\}$; there is one-way-trade from country $j$ to country $i$ if $\bar{t}\left(\lambda_{j}\right) \leq t<\bar{t}\left(\lambda_{i}\right)$; finally, there is no trade if $t \geq \max \left\{\bar{t}\left(\lambda_{i}\right), \bar{t}\left(\lambda_{j}\right)\right\}$.

Figure 1 shows how the trade pattern changes with the level of trade costs, $t$, and the international allocation of capital, $\lambda_{i}$. It also displays the loci of the thresholds $\bar{t}\left(\lambda_{i}\right)$ and $\bar{t}\left(\lambda_{j}\right)$ that divide the domain of trade costs and capital allocations into four regimes: two-way trade (West), no trade (East) and one-way trade (middle North and middle South). The figure sheds light on new features that have been neglected in the literature. First, when trade costs are very low $(t<\bar{t}(1))$, all firms export from every country to the other one because geographical separation does not suffice to protect domestic varieties from foreign competition. Conversely, under very high trade costs $(t>\bar{t}(0)=1)$, no firm export and domestic firms are always protected against competition from abroad.

\section{Insert Figure 1 about here}

Furthermore, one-way trade may arise when $\bar{t}(1)<t<\bar{t}(0)$. We have to distinguish between the following two configurations. On the one hand, when $\bar{t}(1)<t<\bar{t}(1 / 2)$, one-way trade takes place from country $j$ to country $i$ because fewer varieties are produced in country $i\left(\lambda_{i}<\lambda_{j}\right)$. This is because competition is sufficiently soft in this country to allow country $j$-varieties to be exported. In contrast, owing to the large number of local producers competition in country $j$ is too tough to permit the entry of foreign varieties. As firms relocate from $j$ to $i$ ( $\lambda_{i}$ increases), the economy moves to two-way trade. This is because competition is relaxed in country $j$, while trade costs are not high enough to prevent trade from $i$ to $j$. By contrast, when most varieties are produced in country $i$ (high $\lambda_{i}$ ), the corresponding market becomes too competitive to permit imports from $j$. Competition in country $j$ is then sufficiently soft for country $i$-firms to export.

On the other hand, when $\bar{t}(1 / 2)<t<\bar{t}(0)$, one-way trade occurs for small and large values of $\lambda_{i}$. However, instead of two-way trade, autarky now prevails when countries become less 
dissimilar in terms of capital allocation $\left(\lambda_{i}\right.$ close to $\left.1 / 2\right)$. In this case, competition becomes tougher in country $j$ but remains intense enough in country $i$, implying that trade costs are sufficiently high to prevent foreign varieties to be exported.

This analysis shows that, regardless of the level of sectoral disaggregation and in the absence of fixed cost to export, the toughness of competition is critical in determining trade patterns. As $n$ steadily decreases, the global economy typically moves from autarky to two-way trade through one-way trade. Thus, the nature of trade may be explained by differences in market competitiveness. Note also that countries must have different sizes for one-way trade to occur. Indeed, when countries are symmetric, the economy shifts directly from autarky to two-way trade at $t=\bar{t}(1 / 2)$.

Trade flows We now discuss the aggregate value of country $j$ 's export,

$$
X_{j} \equiv \lambda_{j} N \theta_{i} p_{j i}^{*} q_{j i}^{*}
$$

which can be broken down between the extensive and intensive margins of trade, $\lambda_{j} N$ and $\theta_{i} e_{j i}^{*}\left(t, \lambda_{j}\right)$ where

$$
e_{j i}^{*}\left(t, \lambda_{j}\right) \equiv p_{j i}^{*} q_{j i}^{*}=\left(q_{j i}^{*}+t\right) q_{j i}^{*}
$$

is a country- $i$ consumer's expenditure on manufactured import from country $j$.

Since $q_{j i}^{*}$ and $p_{j i}^{*}$ move in opposite directions when $t$ falls, the impact on $e_{j i}^{*}$ is a priori undetermined. The intensive margin increases with a fall in trade costs if and only if

$$
\frac{\mathrm{d}}{\mathrm{d} t} e_{j i}^{*}\left(t, \lambda_{j}\right)=\left(2 q_{j i}^{*}+t\right) \frac{\mathrm{d} q_{j i}^{*}}{\mathrm{~d} t}+q_{j i}^{*}=-\frac{t(n+2)^{2}-n \lambda_{j}\left(n t \lambda_{j}+2\right)}{2(n+2)^{2}} \leq 0
$$

which holds if and only if

$$
\frac{2 n \lambda_{j}}{(n+2)^{2}-n^{2} \lambda_{j}^{2}} \equiv \tilde{t}\left(\lambda_{j}\right) \leq t \leq \bar{t}\left(\lambda_{j}\right)
$$

Thus, the intensive margin increases with a fall in trade costs when $t$ is not too low $\left(t \geq \tilde{t}\left(\lambda_{j}\right)\right)$. In this case, trade costs are sufficiently large for the prices of imported varieties in country $i$ to be in the elastic segment of the demand function. A fall in trade costs therefore entice the exporting firms to cut their price, which raises more than proportionately consumption levels, thus boosting the intensive margin. When (13) holds for $i, j=H, F$ and $i \neq j$, this implies

$$
\frac{\mathrm{d}}{\mathrm{d} t}\left(X_{H}+X_{F}\right)<0
$$

which agrees with the various estimations of the gravity equation (Disdier and Head, 2008). 
By contrast, the intensive margin decreases with a fall in trade costs when the latter are low $\left(t<\tilde{t}\left(\lambda_{j}\right)\right.$ for $i, j=H, F$ and $\left.i \neq j\right)$. Then, prices are low and consumers have inelastic demands for the varieties. A fall in trade costs reduces product prices further down but consumers do not raise much their consumption. As a consequence, the intensive margin drops with a fall in trade costs. Putting things together, we may conclude that, contrary to general belief, $a$ consumer's expenditure on a variety does not monotonically increase with falling trade costs.

Furthermore, unlike $q_{j i}^{*}$ that depends upon $n$ only, $X_{j}$ is affected differently by $\gamma$ and $N$. To this end, we distinguish again between the intensive and extensive margins of trade. On the one hand, raising $\gamma$ affects only the intensive margin, and thus lowers the value of export. Indeed, since the manufactured product is less differentiated, competition among domestic (foreign) varieties, as well as competition between domestic and foreign varieties, is tougher. As a consequence, exporting becomes harder. On the other hand, raising $N$ also reduces the intensive margin but increases the extensive margin, thus making its impact ambiguous. Nevertheless, differentiating $X_{j}$ yields

$$
\frac{\mathrm{d} X_{j}}{\mathrm{~d} N} \propto q_{j i}^{*}\left(q_{j i}^{*}+t\right)+N\left(2 q_{j i}^{*}+t\right) \frac{\mathrm{d} q_{j i}^{*}}{\mathrm{~d} N}
$$

which can be shown to be negative. Therefore, the value of export decreases with the total number of varieties. As $N$ increases, more varieties are produced in both countries, thus strengthening the extensive margin. However, the pro-competitive effect sparked by the larger number of domestic varieties dominates the variety effect generated by the larger number of foreign varieties.

In the next section, we discuss the allocation of capital and firms between countries-regions when capital-holders are free to choose where to invest.

\section{International allocation of capital}

Another important facet of the market integration process is the international mobility of capital. By allowing capital to move from one country to the other, the competitiveness of each national market changes through the number of domestic firms, which in turn affects the incentives to export. Hence, although firms are homogeneous, the conditions for firms to export change with the international allocation of capital. This in turn implies that the nature of trade may change with the relocation of firms. To highlight those effect, we now assume that the allocation of capital $\lambda_{i}$ is endogenous and chosen by the investors. In what follows, we first define the equilibrium allocation of capital, then study this equilibrium for each trade pattern 
and, finally, synthesize our results.

Let $r_{i}$ be the endogenous return of a unit of capital invested in country $i$. For any allocation of capital $\lambda_{i}$, each firm earns the profit $\Pi_{i}-f r_{i}$ where $\Pi_{i}$ is the operating profit defined by

$$
\Pi_{i}=\left\{\begin{array}{cc}
\pi_{i i}+\pi_{i j} & \text { if country } i \text {-firms export to country } j \\
\pi_{i i} & \text { if country } i \text {-firms do not export. }
\end{array}\right.
$$

where $\pi_{i i}=\theta_{i}\left(p_{i i}^{*}\right)^{2}$ and $\pi_{i j}=\theta_{j}\left(p_{i j}^{*}-t\right)^{2}$. In a competitive capital market, the capital return $r_{i}$ is determined by a bidding process for capital among firms, which comes to an end when no firm can earn a strictly positive profit. That is, firms' operating profits are entirely absorbed by the capital return so that $r_{i}=\Pi_{i} / f$.

At the spatial equilibrium, no capital-owner can get a higher return by relocating her capital to another country. Formally, at an interior equilibrium $\left(0<\lambda_{i}^{*}<1\right)$, we have $r_{H}=r_{F}=r$, where $r$ is such that all profits are equal to zero; we have a corner equilibrium at $\lambda_{i}^{*}=1$ when $r_{i}$ exceeds $r_{j}$ for all values of $\lambda_{i}$. For conciseness, we will use the notation for the country-size asymmetry:

$$
\theta \equiv \theta_{H} / \theta_{F} \in[1, \infty)
$$

with $\theta=1$ if and only if the two countries have the same size.

Three cases may arise according to the nature of the trade pattern. In each case, two types of equilibria may arise. First, the equilibrium is interior and country $H$ produces a larger number of varieties than country $F\left(1 / 2<\lambda_{H}^{*}<1\right)$. Second, all firms agglomerate in country $H\left(\lambda_{H}^{*}=1\right)$. In what follows, we focus on the more relevant case of an interior equilibrium. The analysis of the corner equilibrium is provided in Appendix 3.

\subsection{Two-way trade}

Suppose that the manufactured good is imported from both countries. Proposition 2 then implies that the condition

$$
t<\min \left\{\bar{t}\left(\lambda_{H}\right), \bar{t}\left(\lambda_{F}\right)\right\}
$$

holds. Since capital-owners seek the highest rate of return, the relocation incentives are given by the profit differential $\left(\pi_{H H}+\pi_{H F}\right)-\left(\pi_{F F}+\pi_{F H}\right)$ in which the equilibrium prices are given by (9) with $\mu_{i}=\lambda_{i}$, and thus $N_{i}=N$, for $i=H, F$. This expression has a unique zero given by

$$
\lambda_{H}^{*}=\frac{1}{2}+\left(\theta_{H}-\theta_{F}\right) \frac{2-t}{n t}>\frac{1}{2} .
$$

Note that there is a home market effect $\lambda_{H}^{*}>\theta_{H}$ because $t<\bar{t}(1 / 2)<\bar{t}\left(\lambda_{H}\right)$. 
When $\lambda_{H}^{*}<1$ and trade costs are sufficiently low to satisfy (14), some simple algebra shows that the following two conditions are necessary and sufficient:

$$
\theta<\rho_{0} \equiv \frac{2(2-t)+n t}{2(2-t)-n t}
$$

and

$$
\theta<\rho_{1} \equiv \frac{2(4-3 t)-t n}{t(2+n)}
$$

where $\rho_{0}$ increases and $\rho_{1}$ decreases with $t$.

Figure 2 depicts the domains of trade costs, $t$, and the country-size asymmetry, $\theta \equiv \theta_{H} / \theta_{F}$, which support the equilibrium with two-way, one-way and no way trade when there is partial or full agglomeration of firms. The domain of the two-way trade equilibrium described by (15) lies below the curves denoted by $\rho_{0}(t)$ and $\rho_{1}(t)$.

\section{Insert Figure 2 about here}

Looking at the curves $\rho_{0}$ and $\rho_{1}$ in Figure 2, i.e. (16) and (17) hold, leads to the following conclusions. First, two-way trade is more likely when countries are more similar (lower $\theta$ ). Second, two-way trade is more likely when trade costs take intermediate values. Indeed, low trade costs not only facilitate trade but also entice firms to move away from the smaller country so that no firms would remain to export from this country. Third, country $F$ exports less on both the extensive and intensive margins. However, the remaining $F$-firms keep exporting to country $H$, which means that the market integration effect triggered by falling trade costs dominates the competition effect generated by the larger number of firms located in country $H$. Last, two-way trade becomes more likely for smaller trade costs and less likely for larger ones when the degree of competitiveness increases. Indeed, when $n$ rises, the curve $\rho_{0}$ is shifted upward, whereas the curve $\rho_{1}$ is shifted downward. In sum, when the global economy becomes more competitive, a few firms will seek protection in the smaller country but will stop exporting because the larger market is very competitive.

To sum up, we have:

Proposition 3 If $\theta<\rho_{0}$ and $\theta<\rho_{1}$, then there exists a unique spatial equilibrium involving more firms in the larger country with two-way trade. Furthermore, when $\theta \geq \rho_{0}$ and $t<\hat{t} \equiv$ $2 /(2+n)$, there is full agglomeration and one-way trade from $H$ to $F$.

This proposition allows determining firms' size as well as the value of export. Indeed, we know that $q_{i i}^{*}=p_{i i}^{*}$ and $q_{j i}^{*}=p_{i i}^{*}-t / 2$, so that $q_{i i}^{*}=q_{j i}^{*}+t / 2$. Therefore, the consumption of 
a domestic variety always exceeds the consumption of a foreign variety, the reason being that the former is sold at a lower price than the latter. As a result, the size of a firm set up in the larger country exceeds that of a firm located in the smaller country. Indeed, the size of a firm located in country $i$ is given by

$$
Q_{i}^{*} \equiv \theta_{i} q_{i i}^{*}+\theta_{j} q_{i j}^{*}=\theta_{i} q_{i i}^{*}+\theta_{j}\left(q_{j j}^{*}-t / 2\right) .
$$

Hence, we have

$$
Q_{i}^{*}-Q_{j}^{*}=\left(\theta_{i}-\theta_{j}\right) \frac{t}{2} .
$$

This finding agrees with Manning (2010) who finds a robust correlation between average firm size and total labor market size. It sharply contrasts with the firms' behavior discussed in CES models where firms' production scales are independent of market sizes because of the absence of pro-competitive effects.

Trade flows and equilibrium capital distribution In what follows, we first determine the individual and global value of export. It follows from (11) and $\lambda_{H}^{*}>\lambda_{F}^{*}$ that a country $F$-consumer spends more on an imported variety that a country $H$-consumer: $e_{H F}^{*}\left(t, \lambda_{H}^{*}\right)>$ $e_{F H}^{*}\left(t, \lambda_{F}^{*}\right)$. Furthermore, the home market effect implies that $\theta_{F} \lambda_{H}^{*}>\theta_{H} \lambda_{F}^{*}$ holds. As a consequence, we have

$$
X_{H}^{*}=\theta_{F} \lambda_{H}^{*} e_{H F}^{*}\left(t, \lambda_{H}^{*}\right)>\theta_{H} \lambda_{F}^{*} e_{F H}^{*}\left(t, \lambda_{F}^{*}\right)=X_{F}^{*} .
$$

Hence, at the equilibrium distribution of capital, the larger country is a net exporter of the manufactured good.

This result is consistent with the following empirical observations. The OLS estimation of the equation $\ln$ (export value) $=\alpha+\beta \ln$ (number of manufacturing plants) over the 341 French employment areas in 2008 yields $\beta=1$.4. Thus, on average, French export increases by 40 percent when the number of plants within the same employment area doubles. Repeating the same exercise for Japanese manufacturing plants located in 2,032 towns and villages for 2005, we obtain $\beta=1.29$.

To sum up,

Proposition 4 Under two-way trade, firms' sizes are larger in the larger country. Furthermore, the value of aggregate manufacturing exports from the larger market exceeds that from the smaller one. 
Turning to the impact of trade costs on export values, we get

$$
\begin{aligned}
& \frac{d X_{H}^{*}}{d t}=\theta_{F}\left[\lambda_{H}^{*} \frac{\partial e_{H F}^{*}}{\partial t}+\frac{d \lambda_{H}^{*}}{d t}\left(e_{H F}^{*}+\lambda_{H}^{*} \frac{\partial e_{H F}^{*}}{\partial \lambda_{H}}\right)\right] \\
& \frac{d X_{F}^{*}}{d t}=\theta_{H}\left[\lambda_{F}^{*} \frac{\partial e_{F H}^{*}}{\partial t}+\underset{+/-}{\frac{d \lambda_{F}^{*}}{d t}}\left(\begin{array}{c}
e_{F H}^{*}+\lambda_{F}^{*} \frac{\partial e_{F H}^{*}}{\partial \lambda_{F}} \\
+
\end{array}\right)\right]
\end{aligned}
$$

where we have used $\partial e_{H F}^{*} / \partial \lambda_{H}>0$ and $\partial e_{F H}^{*} / \partial \lambda_{F}>0$, which follow from (7) and (11). Therefore, a fall in trade costs gives rise to one direct and two indirect effects through firms' relocation. First, it improves the accessibility of export markets (first term in the square bracket). As shown by (13), this increases (decreases) the incentives to export, and thus the intensive margins when trade costs are not too low (high). Second, the fall in trade cost entices firms to relocate in the larger market and to re-export from there. Extensive margins to export increase in the larger country and decrease in the smaller market (first term in the parentheses). Finally, firms' relocation makes the larger market more competitive and the smaller market less competitive. As a consequence, firms increase their export from the larger country and decrease them from the smaller one. Hence, intensive margins to export increase in the larger country and fall in the other (second term in the parentheses).

When trade costs are not too small $\left(t>\tilde{t}\left(\lambda_{H}^{*}\right)\right)$, the above three effects are congruent: the aggregate export $X_{H}^{*}$ monotonically increases with a fall in trade costs. However, the direct effect conflicts with the two indirect effects when trade costs are small $\left(t<\tilde{t}\left(\lambda_{H}^{*}\right)\right)$, and thus the impact of lowering $t$ is ambiguous. Consider first the two-way trade case where $\lambda_{H}^{*}<1$. We show in Appendix 4 that $X_{H}^{*}$ always increases with a fall in trade costs when the industry gets fully agglomerated $\left(\lambda_{H}^{*} \rightarrow 1\right)$ and when country $H$ stops importing $\left(t \rightarrow \bar{t}\left(\lambda_{H}^{*}\right)\right)$. Simulations confirm this result for intermediate values of $t$. Consider then the case where $\lambda_{H}^{*}=1$. Then, $X_{H}^{*}$ decreases with falling trade costs if and only if $t<\tilde{t}(1)$. Since it is readily verified that $0<\tilde{t}(1)<\hat{t}$, we can conclude that $X_{H}^{*}$ is a non-monotone function of $t$ over the interval $[0, \hat{t}]$.

Furthermore, the export value of the smaller country $X_{F}^{*}$ is also a non-monotone function of trade costs over the interval $\left[t_{0}, t_{1}\right]$. To show it, let us fix the country-size asymmetry, $\theta$, and define two thresholds for trade costs: namely, the trade cost $t_{0}$ below which full agglomeration occurs $\left(\lambda_{H}^{*}=1\right.$ and $\left.\lambda_{F}^{*}=0\right)$ and the trade cost $t_{1}$ below which firms start exporting from the smaller to the larger country under two way trade $\left(q_{F H}^{*}=0\right)$. That is, $t_{0}$ and $t_{1}$ are such that $\theta=\rho_{0}\left(t_{0}\right)=\rho_{1}\left(t_{1}\right)$ and $t_{0}<t_{1}$ (see Figure 2). Consider now the case of falling trade costs. When trade costs exceeds $t_{1}$, no firm in the smaller market export. When trade costs falls from and below $t_{1}$, each firm in the smaller market starts exporting and increases its export 
from zero to a positive level. In this case, the intensive margin to export drives the changes in the aggregate export from the smaller market so that the aggregate manufactured export from the smaller market increases from zero to positive values. When trade costs approach $t_{0}$ from above, fewer and fewer firms remain in the smaller country $\left(\lambda_{F}^{*} \rightarrow 0\right)$. The aggregate export from this country is determined mainly by its extensive margin to export and the aggregate manufactured export from the smaller market falls. Finally, for trade costs lower than $t_{0}$, there are no firms in the smaller market and therefore no export. In sum, the aggregate export from the smaller market is a non-monotone function of trade costs: when trade costs take on high values, a fall in trade costs first raises aggregate export through its effect on intensive margins and, then, decreases it through its effect of extensive margins when trade costs take low values.

Thus, we have:

Proposition 5 The export value of the larger country first increases and then decreases with falling trade costs on $[0, \hat{t}]$. Furthermore, the export value of the smaller country is also nonmonotone on $\left[t_{0}, t_{1}\right]$.

Observe that global trade encompasses the export of both manufactured good and the numéraire. We know that the larger country exports only the manufactured good for a value $X_{H}^{*}$ while the smaller country exports both its manufactured varieties for a value $X_{F}^{*}$ and the numéraire for a value equal to $\theta_{H}\left(q_{0 H}-\bar{q}_{0}\right)$. Because market clearing leads to a balanced trade $\left(X_{H}^{*}=X_{F}^{*}+\theta_{H}\left(q_{0 H}-\bar{q}_{0}\right)\right)$, the value of global trade is just equal to $2 X_{H}^{*}$. Therefore, the value of global trade varies non monotonically when trade costs fall.

\subsection{No trade}

As in Behrens (2005b), we now assume that no firms export. Proposition 2 then implies that

$$
t \geq \max \left\{\bar{t}\left(\lambda_{H}\right), \bar{t}\left(\lambda_{F}\right)\right\}
$$

Relocation incentives are given by $\pi_{H H}-\pi_{F F}$ in which the equilibrium prices are now given by (9) where $\mu_{i}=0$, and thus $N_{i}=\lambda_{i} N$, for $i=H, F$. The unique zero of this expression is equal to

$$
\lambda_{H}^{*}=\frac{1}{2}+\frac{1}{2} \frac{\sqrt{\theta_{H}}-\sqrt{\theta_{F}}}{\sqrt{\theta_{H}}+\sqrt{\theta_{F}}} \frac{4+n}{n} \geq \frac{1}{2} .
$$

Therefore, the international allocation of capital remains biased toward the larger country $H$. This bias falls when the economy becomes more competitive (larger $n$ ). Since $\lambda_{H}^{*}$ exceeds $\lambda_{F}^{*}$, 
market $H$ is more competitive than market $F$. Therefore, it is always less profitable for firms located in country $F$ to export than for those located in country $H$. This implies that (19) boils down to

$$
t \geq \bar{t}\left(\lambda_{F}^{*}\right)=\frac{2}{2+n \lambda_{F}^{*}} .
$$

This condition becomes less stringent as the number of firms in country $F$ increases, thus deterring export to $F$ because competition therein is tougher.

It is readily verified that $\lambda_{H}^{*}<1$ is equivalent to

$$
\theta<\rho_{2} \equiv\left(1+\frac{n}{2}\right)^{2}
$$

which is independent of $t$ since there is no trade. Furthermore, by plugging $\lambda_{F}^{*}=1-\lambda_{H}^{*}$ into (20), this condition becomes

$$
\theta \leq \rho_{3} \equiv \frac{1}{4}[n t-2(1-2 t)]^{2} .
$$

Since $\theta \geq 1$, it must be that $t \geq 4 /(n+4)$ for this inequality to hold. Thus, as expected, trade costs must be sufficiently large and/or the global economy sufficiently competitive for the no-trade case to arise. Note also that $\rho_{3}<\rho_{2}$ when $t<1$.

To sum up, we have:

Proposition 6 If $\theta<\rho_{2}$ and $\theta \leq \rho_{3}$, then there exists a unique spatial equilibrium involving more firms in the larger country and no trade. Furthermore, there is full agglomeration in the larger country and no trade when $\theta \geq \rho_{2}$ and $t \geq 1$.

\subsection{One-way trade}

Suppose, last, that firms export only from country $i$ to country $j$. Proposition 2 then implies

$$
\bar{t}\left(\lambda_{i}\right) \leq t<\bar{t}\left(\lambda_{j}\right)
$$

For this condition to hold, it must be that $\lambda_{i}>\lambda_{j}$, which means that the exporting country hosts more firms than the other.

Under one-way trade from country $i$ to country $j$, the relocation incentives are given by the operating profit differential $\Delta \pi_{i}=\left(\pi_{i i}+\pi_{i j}\right)-\pi_{j j}$ in which the equilibrium prices are given by (9) where country $i$-firms export $\left(\mu_{i}=\lambda_{i}\right)$, whereas country $j$-firms do not $\left(\mu_{j}=0\right)$. Therefore, the numbers of varieties at consumers' disposal in country $j$ and $i$ are, respectively, $N_{j}=N$ and $N_{i}=\lambda_{i} N$. This yields

$$
\Delta \pi_{i} \propto\left[\theta_{i}\left(\frac{1}{2+\lambda_{i} n}\right)^{2}-\theta_{j} \frac{t}{2}\left(\frac{2+\lambda_{i} n t}{2+n}-\frac{t}{2}\right)\right]
$$


which is monotonically decreasing in $\lambda_{i}\left(\partial \Delta \pi_{i} / \partial \lambda_{i}<0\right)$. Thus, when only country $i$-firms export to country $j,(22)$ has a unique zero.

In the presence of trade costs, firms always have an advantage to operate in the larger country because this one offers a better access to the larger pool of local consumers. This advantage attracts more firms but fosters competition in the larger market, thus reducing the foreign firms' incentives to export into this market. More precisely, we show in Appendix 5 that one-way trade always implies trade from the larger to the smaller country (i.e. $i=H$ and $j=F)$. In this case, the unique solution to $\Delta \pi_{H}=0$ involves an interior solution if and only if operating profits in country $H$ are lower than those made in $F$ when all firms are located in $H$ : $\pi_{H H}+\pi_{H F}<\pi_{F F}$ at $\lambda_{H}=1$. Plugging $\lambda_{H}=1$ in (22) shows that this condition is equivalent to

$$
\theta<\rho_{4} \equiv \frac{(2+n) t}{4}[2(2-t)+t n] .
$$

Furthermore, the above solution must fulfill the conditions (21) for $i=H$ and $j=F$. It is readily verified that these two conditions are equivalent to

$$
\lambda_{H}^{*} \geq 2 \frac{1-t}{n t} \quad \text { and } \quad \lambda_{H}^{*}>1-\frac{2(1-t)}{n t} .
$$

The former inequality holds if and only if $\theta \geq \rho_{1}$, while the latter holds if and only if $\theta>\rho_{3}$. This can be shown by plugging each bound of (21) in the equilibrium condition $\Delta \pi_{H}=0$.

As shown in Figure 2, the level of trade costs does not have a monotone impact on the range of country-size asymmetry sustaining one-way trade. Consider a situation in which $\theta$ steadily decreases to $\rho_{1}$. Then, the economy shifts from one-way trade to two-way trade. This is because the relative size of the larger country gets smaller, which weakens competition in this market and fosters import. In contrast, when $\theta$ steadily decreases to $\rho_{3}$, the economy shifts to no-trade because the smaller country is more competitive and protected by higher trade costs. It is, therefore, more difficult to penetrate. Last, it can be shown that both the loci $\rho_{3}$ and $\rho_{4}$ are shifted upward when the degree of competitiveness $n$ increases, while the gap between $\rho_{4}$ and $\rho_{3}$ widens with $n$.

The expression (22) may be used to uncover the impact of country-size asymmetry and trade costs. Indeed, it is readily verified that

$$
\frac{\partial \Delta \pi_{H}}{\partial \theta}>0 \quad \text { and } \quad \frac{\partial \Delta \pi_{H}}{\partial t}<0 .
$$

Thus, we have:

$$
\frac{\mathrm{d} \lambda_{H}^{*}}{\mathrm{~d} \theta}=-\frac{\partial \Delta \pi_{H}}{\partial \theta} / \frac{\partial \Delta \pi_{H}}{\partial \lambda_{H}}>0 \quad \text { and } \quad \frac{\mathrm{d} \lambda_{H}^{*}}{\mathrm{~d} t}=-\frac{\partial \Delta \pi_{H}}{\partial t} / \frac{\partial \Delta \pi_{H}}{\partial \lambda_{H}}<0 .
$$


In words, the larger country hosts a growing share of firms when its relative size rises, whereas lowering trade costs leads the manufacturing firms to get more agglomerated in the larger country. Consequently, firms that quit the less competitive and smaller country find it profitable to export their output to their country of origin. To put it differently, even though firms are homogeneous, their locational choices determine their attitudes toward export. This is to be contrasted with the recent literature that explains export structure with firms' technological heterogeneity (Melitz and Ottaviano, 2008).

We may summarize our results as follows.

Proposition 7 If $\theta \geq \rho_{1}, \theta>\rho_{3}$ and $\theta<\rho_{4}$, then there exists a unique spatial equilibrium involving more capital in the larger country and one-way trade from the larger to the smaller country. Furthermore, full agglomeration with one-way trade prevails when $\theta \geq \rho_{4}$ and $\hat{t} \leq t<$ 1.

Finally, it is worth discussing shortly the trade flows in the one-way trade configuration. First, since the smaller country does not export its differentiated varieties, it is clear that the export value of differentiated goods is larger in the larger country: $X_{H}^{*}>X_{F}^{*}=0$. Second, because trade is balanced, the impact of trade cost on global trade is the same as its impact on $X_{H}^{*}$. The impact of trade cost on $X_{H}^{*}$ is still given by the first line in (18). Therefore a fall in trade costs encompasses the same direct and indirect effects on trade. It first enhances the market access and increases the intensive margin of trade of country $H$-firms when $t$ is not too low. It also triggers capital relocation toward the larger market and widens the extensive margin to trade from this market. Finally, it softens competition in the smaller country and increases further export to $F$. All in all, a fall in trade costs increases the aggregate export of the larger country when trade costs are not too small.

\subsection{Synthesis}

The above analysis describes the equilibrium conditions for the existence of a unique spatial equilibrium in the case of two-way trade, one-way trade and no trade. As illustrated by Figure 2 , these conditions define several domains that form a partition of the positive quadrant in the plane $(t, \theta)$. We may collate those conditions in the following proposition, which shows how globalization affects the nature of trade and of economic geography, where we have set

$$
\hat{\theta} \equiv 1+\frac{2 n}{2+n}
$$

which solves $\rho_{0}(\hat{t})=\rho_{1}(\hat{t})=\rho_{4}(\hat{t})=\hat{\theta}$ (see Figure 2). 
Proposition 8 As trade costs steadily decrease, the economy goes through the following sequence of stages:

(i) For small country-asymmetries $(\theta<\hat{\theta})$, the larger country accommodates a larger number of firms while the economy displays sequentially no trade, one-way trade and two-way trade; finally, it involves full agglomeration with one-way trade.

(ii) For intermediate values of country-asymmetries $\left(\hat{\theta}<\theta<\rho_{2}\right)$, the larger country accommodates a larger number of firms with first no trade and, then, one-way trade; finally, it involves full agglomeration with one-way trade.

(iii) For large country-asymmetries $\left(\rho_{2}<\theta\right)$, the economy involves full agglomeration in the larger country with first no trade and then one-way trade.

As for the trade patterns when firms are free to choose their locations, the following remarks are in order. First, a fall in trade cost has a different impact on the value of trade flows for low and high trade costs. Indeed, we have seen that the export value $X_{F}^{*}$ is a non-monotone function of trade cost, which is depicted in Figure 3. For high trade costs, a fall in trade cost raises the export value $X_{F}^{*}$ because firms in the smaller country face a better access to the larger country, and thus are able to export. However, when trade costs are sufficiently low, $X_{F}^{*}$ falls because firms quit the smaller country.

Figure 3 also shows that the export value $X_{H}^{*}$ from the larger country is a non-monotone function of trade cost. Indeed, at very high trade costs, no country export. For intermediate trade cost values, only the larger country is able to export so that a fall in trade cost increases the corresponding firms' access to the smaller country, which boosts their exports and their export value. For lower trade costs, trade occurs in both directions. In this event, a fall in trade cost continues to increase the export value from the larger country. Finally, for sufficiently low trade costs, all firms agglomerate in the larger country and export from there. Only the intensive margins are then at work. Figure 3 shows that steadily decreasing trade costs implies that the export value of $H$ first, increases and, then, decreases. The reason lies in our discussion of the impact of trade costs on the intensive margin.

\section{Insert Figure 3 about here}

Second, the nature of trade may have an important impact on how country-size asymmetry affects the trade values. First, high country-size asymmetry ( $\theta$ rises) do not lead to monotone changes in export values $\left(X_{H}^{*}\right.$ and $\left.X_{F}^{*}\right)$. As shown in the left hand panel of Figure 4 , a stronger size discrepancy first increases the export value from the larger country as well as the total export value when there is two-way trade. This follows from the market access effect: as the 
larger market grows, more firms relocate therein so that the consumers in the smaller country must import more varieties. However, once all firms agglomerate in the larger country the export value falls with a higher country-size asymmetry. This is because the demand from the smaller country decreases owing to its falling population.

By contrast, in the right hand panel of Figure 4, trade costs are so high that two-way trade never arises. In this case, firms spread between the two countries. When the country sizes are similar there is no trade. For larger $\theta$, the smaller country hosts fewer firms, which dampens the intensity of competition in $F$ and entices the $H$-firms to export. Hence, there is partial agglomeration and one-way trade. An increase in the country-size asymmetry, however, raises the export value from the larger country. This is because some firms move to the larger country and start exporting to the smaller country where competition is softer owing to the smaller number of firms set up there. Finally, for large enough country-size asymmetry, all firms agglomerate in the larger market. As a result, any further rise in the country-size asymmetry reduces the export value because the shrinking population in $F$ has a lower demand.

Insert Figure 4 about here

\section{Concluding remarks}

This paper has shown how trade liberalization may span a wide range of cases, which reflects the diversity displayed by commodity flows in world trade. In particular, we have seen that the nature and intensity of trade does not depend only upon the degree of openness of the economy. If an industry supplies varieties that are close substitutes, there will be little trade because each market is governed by unleashed competition. How firms are distributed across countries is another critical determinant, the reason being that their locations affect the intensity of competition within each country. For example, foreign firms will find it more difficult to export to a country that accommodates a larger number of domestic firms because local prices are lower. Last, when more capital is allocated to a particular sector, the intensity of trade is lowered because a larger number of firms compete in the global economy. In sum, all parameters and policies that influence the degree of market competition are likely to have a strong impact on trade and the location of firms. These effects cannot be studied under the CES model of monopolistic competition because (i) the equilibrium markup is independent of the number of competition varieties and (ii) the demand for any variety is always positive.

Admittedly, the assumption of homogeneous firms has vastly simplified our analysis and one may wonder what our results become once it is recognized that firms are heterogeneous. To 
this end, we may appeal to Nocke (2006), Okubo et al. (2010) and Picard and Okubo (2012) to predict the possible impact of firm heterogeneity on our results. These authors show that market integration fosters the spatial sorting of firms, the more efficient choosing to locate in the larger country and the less efficient in the smaller one. Since firms established in the smaller country face impediments to export to the larger one when they are homogeneous, this effect will be strengthened when these firms are also the least efficient ones.

\section{References}

[1] Baldwin, Richard and James Harrigan. 2011. "Zeros, quality and space: trade theory and trade evidence," The American Economic Journal: Microeconomics, 3, 60-88.

[2] Behrens, Kristian. 2004. "Agglomeration without trade: how non-traded goods shape the space-economy," Journal of Urban Economics, 55, 68-92.

[3] Behrens, Kristian. 2005a. "How endogenous asymmetries in interregional market access trigger regional divergence," Regional Science and Urban Economics, 35, 471-492.

[4] Behrens, Kristian. 2005b. "Market size and industry location: traded vs non-traded goods," Journal of Urban Economics, 58, 24-44.

[5] Bresnahan Timothy F. and Peter C. Reiss. 1991. "Entry and competition in concentrated markets," Journal of Political Economy, 99, 977-1009.

[6] Chen, Nathalie, Jean Imbs and Andrew Scott. 2009. "The dynamics of trade and competition," Journal of International Economics, 77, 50-62.

[7] Disdier, Anne-Celia, and Keith Head. 2008. "The puzzling persistence of the distance effect on bilateral trade," Review of Economics and Statistics 90, 37-48.

[8] Irarrazabal, Alfonso, Andreas Moxnes, Opromolla, Luca D. 2013. "The tip of the iceberg: a quantitative framework for estimating trade costs," NBER Working Papers 19236.

[9] Helpman, Elhanan, Marc Melitz, and Stephen Yeaple. 2004. "Export versus FDI with heterogeneous firms," American Economic Review, 94, 300-316.

[10] Helpman, Elhanan, Marc Melitz and Yona Rubinstein. 2008. "Estimating trade flows: trading partners and trading volumes," Quarterly Journal of Economics 123, 441-487. 
[11] Manning, Alan. 2010. "Agglomeration and monoposony power in labour markets," Journal of Economic Geography, 10(5), 1717-1744.

[12] Martin, Philippe and Carol A. Rogers. 1995. "Industrial location and public infrastructure," Journal of International Economics, 39, 335-351.

[13] Melitz, Marc. 2003. "The impact of trade on intraindustry reallocations and aggregate industry productivity.," Econometrica, 71, 1695-1725.

[14] Melitz, Marc and Gianmarco I.P. Ottaviano. 2008. "Market size, trade, and productivity," Review of Economics Studies, 75, 295-316.

[15] Nocke, Volcker. 2006. "A gap for me: entrepreneurs and entry," Journal of the European Economic Association, 4, 929-955.

[16] Okubo, Toshihiro, Pierre M. Picard and Jacques-François Thisse. 2010. "The spatial selection of heterogeneous firms," Journal of International Economics, 82, 230-237.

[17] Ottaviano, Gianmarco I.P., and Jacques-François Thisse. 2004. "Agglomeration and economic geography," in Henderson, J.V., Thisse, J.-F. (eds.), Handbook of Regional and Urban Economics, volume 4. North-Holland, Amsterdam, pp.2563-2608.

[18] Picard, Pierre M., and Okubo Toshihiro. 2012. "Firms' location under demand heterogeneity", Regional Science and Urban Economics, 42(6), 961-974.

[19] Weinstein, David. 1992. "Competition and unilateral dumping," Journal of International Economics, 32, 379-388.

\section{Appendix 1}

Let $\eta_{k}$ be the Kuhn-Tucker multiplier of the nonnegative consumption constraint of variety $k$. The consumer program may then be re-written as follows:

$$
\begin{aligned}
\max _{q_{k}} \mathcal{L} & =\int_{0}^{N} q_{k} \mathrm{~d} k-\frac{1}{2} \int_{0}^{N} q_{k}^{2} \mathrm{~d} k-\frac{\gamma}{2} \int_{0}^{N} q_{k}\left(\int_{0}^{N} q_{l} \mathrm{~d} l\right) \mathrm{d} k \\
& -\int_{0}^{N} p_{k} q_{k} \mathrm{~d} k+\int_{0}^{N} \eta_{k} q_{k} \mathrm{~d} k+q_{0} .
\end{aligned}
$$


The maximization problem has a concave objective function and convex constraints. Thus, the Kuhn-Tucker conditions are necessary and sufficient condition for a maximum:

$$
\begin{aligned}
& \frac{\mathrm{d} \mathcal{L}}{\mathrm{d} q_{k}} \leq 0 \quad q_{k} \geq 0 \quad \text { and } \quad q_{k} \frac{\mathrm{d} \mathcal{L}}{\mathrm{d} q_{k}}=0 \\
& \frac{\mathrm{d} \mathcal{L}}{\mathrm{d} \eta_{k}} \geq 0 \quad \eta_{k} \geq 0 \quad \text { and } \quad \eta_{k} \frac{\mathrm{d} \mathcal{L}}{\mathrm{d} \eta_{k}}=0
\end{aligned}
$$

where

$$
\begin{aligned}
\frac{\mathrm{d} \mathcal{L}}{\mathrm{d} q_{k}} & =1-q_{k}-\gamma \int_{0}^{N} q_{l} \mathrm{~d} l-p_{k}+\eta_{k} \\
\frac{\mathrm{d} \mathcal{L}}{\mathrm{d} \eta_{k}} & =q_{k} .
\end{aligned}
$$

Because $q_{k}$ and $\eta_{k}$ cannot be simultaneously positive, three cases may arise. First, suppose that $q_{k}>0$. In this case, we have $\mathrm{d} \mathcal{L} / \mathrm{d} q_{k}=0$, which implies

$$
q_{i}=1-p_{i}-\gamma \int_{0}^{N} q_{l} \mathrm{~d} l .
$$

This expression is strictly positive if and only if

$$
p_{k}<\bar{p} \equiv 1-\gamma \int_{0}^{N} q_{l} \mathrm{~d} l .
$$

Second, suppose that $\eta_{k}>0$. Then, $q_{k}=0$ and $\mathrm{d} \mathcal{L} / \mathrm{d} q_{k} \leq 0$, thus implying that

$$
p_{k}-\bar{p} \geq \eta_{k}>0
$$

Last, suppose that $q_{k}=\eta_{k}=0$. In this event, we have

$$
\mathrm{d} \mathcal{L} / \mathrm{d} q_{k} \leq 0 \Longleftrightarrow p_{k}-\bar{p} \geq 0
$$

Accordingly, the solution to the consumer program is given by

$$
q_{k}=\left\{\begin{array}{cr}
1-p_{k}-\gamma \int_{0}^{N} q_{l} \mathrm{~d} l & \text { if } p_{k}<\bar{p} \\
0 & \text { otherwise. }
\end{array}\right.
$$

We are now equipped to construct firms' demands. Since varieties are ranked by increasing price order, let $m(m \leq N)$ be the first variety that is not purchased in that region:

$$
k \geq m \Leftrightarrow p_{k} \geq p_{m} \Longleftrightarrow q_{k}=0
$$

which implies $\int_{0}^{N} q_{l} \mathrm{~d} l=\int_{0}^{m} q_{l} \mathrm{~d} l$. The consumer's demands may therefore be re-written as follows:

$$
q_{k}=\left\{\begin{array}{cr}
1-p_{k}-\gamma \int_{0}^{m} q_{l} \mathrm{~d} l & \text { if } p_{k}<\bar{p} \\
0 & \text { otherwise. }
\end{array}\right.
$$


To determine the value of $\int_{0}^{m} q_{l} \mathrm{~d} l$, we integrate $q_{k}$ over the interval $[0, m]$, so that

$$
\int_{0}^{m} q_{k} \mathrm{~d} k=m-\int_{0}^{m} p_{k} \mathrm{~d} k-\gamma m \int_{0}^{m} q_{l} \mathrm{~d} l
$$

which yields

$$
\int_{0}^{m} q_{k} \mathrm{~d} k=\frac{m-\int_{0}^{m} p_{k} \mathrm{~d} k}{1+\gamma m}
$$

The demand for $k<m$ is then

$$
q_{k}=1-p_{k}-\gamma \int_{0}^{m} q_{l} \mathrm{~d} l=1-p_{k}-\gamma \frac{m-\int_{0}^{m} p_{l} \mathrm{~d} l}{1+\gamma m} .
$$

Since $q_{m}=0$, this yields

$$
p_{m}=\frac{1+\gamma \int_{0}^{m} p_{l} \mathrm{~d} l}{1+\gamma m} \equiv \bar{p} .
$$

Finally, because $p_{k}<p_{m}$, we get $\int_{0}^{m} p_{k} \mathrm{~d} k<m p_{m}$. Using this inequality in the above value for $p_{m}$ yields

$$
p_{m}<\frac{1+\gamma m p_{m}}{1+\gamma m}
$$

or equivalently $p_{m}<1$.

To sum up, we get

$$
q_{k}=\left\{\begin{array}{cl}
\frac{1}{1+\gamma m}-p_{k}+\frac{\gamma}{1+\gamma m} \int_{0}^{m} p_{l} \mathrm{~d} l & \text { if } k<m \\
0 & \text { otherwise. }
\end{array}\right.
$$

and $p_{m}<1$. Proposition 1 applies those results for $m=N_{i}$. Q.E.D.

\section{Appendix 2}

Suppose, first, that all foreign firms export to market $i\left(\mu_{j}=\lambda_{j}\right)$. Then, the number of varieties consumed in region $i$ is $N_{i}=N$ so that the equilibrium price set by region $i$-firms is equal to

$$
p_{i i}^{*}=\frac{1}{2} \frac{2+\operatorname{tn} \lambda_{j}}{2+n} .
$$

By (8), this regime occurs if $t<\bar{t}\left(\lambda_{i}\right)$ where

$$
\bar{t}\left(\lambda_{i}\right) \equiv \frac{2}{2+n \lambda_{i}}
$$

is the expression in (10).

Second, suppose that no foreign firm exports $\left(\mu_{j}=0\right)$. Then, we have $N_{i}=\lambda_{i} N$ and

$$
p_{i i}^{*}=\frac{1}{2+n \lambda_{i}}
$$


where $p_{i i}^{*}<1$. By (8), this regime occurs if $t>\bar{t}\left(\lambda_{i}\right)$.

Finally, an indeterminate number of foreign firms export to market $i$ if $t=\bar{t}\left(\lambda_{i}\right)$. Indeed, plugging $\bar{t}\left(\lambda_{i}\right)$ in (25) yields

$$
p_{i i}^{*}=\frac{1}{2+n \lambda_{i}}
$$

which is independent of $\mu_{j}$. Therefore, the number of exported varieties $\mu_{j}$ can take any value in the interval $\left[0, \lambda_{j}\right]$.

The transition between the export regimes have the following properties. On the one hand, as the value of trade cost increases, the number of varieties exported to region $i$ suddenly switches from $\lambda_{j}$ to 0 at $t=\bar{t}\left(\lambda_{i}\right)$. On the other hand, since $\lambda_{i}$ is here exogenous, one can check

$$
\lim _{t \rightarrow \bar{t}\left(\lambda_{i}\right)_{-}} p_{i i}^{*}=\lim _{t \rightarrow \bar{t}\left(\lambda_{i}\right)_{+}} p_{i i}^{*}=\frac{1}{2+n \lambda_{i}}
$$

which implies that $p_{i i}^{*}$ is continuous at $\bar{t}\left(\lambda_{i}\right)$. As a result, production and profit levels are also continuous functions.

\section{Appendix 3}

Full agglomeration under two-way trade. When $\theta \geq \rho_{0}$, there is full agglomeration in equilibrium $\left(\lambda_{H}^{*}=1\right.$ and $\left.\lambda_{F}^{*}=0\right)$ and, therefore, one-way trade from the larger to the smaller country. For trade to arise, (14) implies that

$$
t<\hat{t} \equiv \frac{2}{2+n}
$$

must hold. Hence, this regime emerges when the two countries are dissimilar enough and trade costs are sufficiently low to sustain trade from the larger to the smaller country (see Figure 2).

Full agglomeration under no trade. If $\theta \geq \rho_{2}$, there is full agglomeration in the bigger country $\left(\lambda_{H}^{*}=1\right)$. However, firms are not enticed to export when $t \geq 1$, as shown by (20) in which $\lambda_{F}^{*}=0$.

Full agglomeration under one-way trade. All firms agglomerate in region $H\left(\lambda_{H}^{*}=1\right)$ if $\theta \geq \rho_{4}(t)$. In this case, the two conditions (21) boil down to $\hat{t} \leq t<1$.

\section{Appendix 4}

We here demonstrate that the larger country's export value $X_{H}^{*}=\theta_{F} \lambda_{H}^{*} e_{H F}^{*}\left(t, \lambda_{H}^{*}\right)$ falls with higher trade costs $t$ at the border of the parameter set supporting two-way trade (i.e. on the 
loci $\rho_{0}(t)$ and $\rho_{1}(t)$ in Figure 2). Plugging the equilibrium value

$$
\lambda_{H}^{*}=\frac{1}{2}+\frac{2-t}{n t} \Delta
$$

where $\Delta \equiv \theta_{H}-\theta_{F} \in[0,1]$, the export value becomes

$$
X_{H}^{*}=\theta_{F} \lambda_{H}^{*} \frac{\left(2+\frac{t n}{2}+\Delta(2-t)\right)^{2}-t^{2}(n+2)^{2}}{4(n+2)^{2}}
$$

and the two-way trade conditions $t<\bar{t}\left(\lambda_{H}\right)<\bar{t}\left(\lambda_{F}\right)$ become

$$
t<t_{0} \equiv \frac{4-4 \Delta}{n-2 \Delta+4}<t_{1} \equiv \frac{4 \Delta+4}{n+2 \Delta+4}
$$

1. Consider the case of full agglomeration where $\lambda_{H}^{*} \rightarrow 1$ (see $\rho_{0}(t)$ in Figure 2 ). In this case, it must be that

$$
\Delta \rightarrow \Phi \equiv \frac{1}{2} \frac{n t}{2-t}
$$

so that

$$
\lim _{\Delta \rightarrow \Phi} \frac{d X_{H}^{*}}{d t}=\frac{-4(n+1) t^{3}+\left(n^{2}+8 n+6\right) t^{2}+2}{2(n+2)^{2} t(t-2)} .
$$

Since $t<1$, this expression is negative if and only if the numerator is positive. It follows from the Descartes rule of signs that the polynomial function of $t$ in the numerator changes its sign only once for $t>0$. This function being positive at $t=0$ and $t=1$, it is positive everywhere on the interval $[0,1]$. Therefore, $d X_{H}^{*} / d t<0$ under two-way trade when $\lambda_{H}^{*} \rightarrow 1$.

2. Consider now the case of partial agglomeration when the smaller country stops exporting (see $\rho_{1}(t)$ in Figure 2). That is, we have

$$
t \rightarrow t_{0}=\frac{4-4 \Delta}{n-2 \Delta+4}
$$

Then,

$\lim _{t \rightarrow t_{0}} \frac{d X_{H}^{*}}{d t}=\frac{\left[\left(\Delta^{3}-4 \Delta^{2}+3 \Delta-1\right) n^{2}-\left(2 \Delta^{4}-6 \Delta^{3}+8 \Delta^{2}-4 \Delta+4\right) n-\Delta\left(4 \Delta^{3}-12 \Delta^{2}+4 \Delta+8\right)\right]}{2(n-2 \Delta+4)(n+2) n(\Delta-1)^{2}}$

is negative because each term in the numerator can be shown to be negative for $\Delta \in[0,1]$.

\section{Appendix 5}

We here prove that the market outcome involving one-way trade implies trade from the larger to the smaller country. Suppose indeed that there is one-way trade from the smaller country $i=F$ to the larger country $j=H$. It then follows from the trade condition (21) that $\lambda_{F}>1 / 2$, 
hence $\lambda_{H}<1 / 2$ : competition in the bigger market must be soft enough for the foreign firms to supply this market, while competition in the smaller market is sufficiently fierce to prevent $H$-firms from exporting to the smaller market. We know that, under each trade regime, the profit differential $\Delta \pi_{H}$ is continuous and decreasing with respect to $\lambda_{H}$. Because $\Delta \pi_{H}$ can be written as a continuous function of all quantities, which are themselves continuous functions of $\lambda_{H}, \Delta \pi_{H}$ is continuous at each transition point. Therefore, the locus $\Delta \pi_{H}$ is continuous and decreasing over the whole interval $[0,1]$ and has, therefore, a unique zero. As shown by Figure 1 , when $\lambda_{H}$ increases from 0 , the economy moves either from one-way trade to no trade, or from one-way trade to two-way trade. Under two-way trade, it is readily verified that $\Delta \pi_{H}>0$ at $\lambda_{H}=1 / 2$, while $\Delta \pi_{H}>0$ also holds $\lambda_{H}=1 / 2$ under no trade. Therefore, for all $\lambda_{H} \leq 1 / 2$, $\Delta \pi_{H}$ must be positive under one-way trade. This means that there exists no equilibrium with $\lambda_{H}<1 / 2$. 


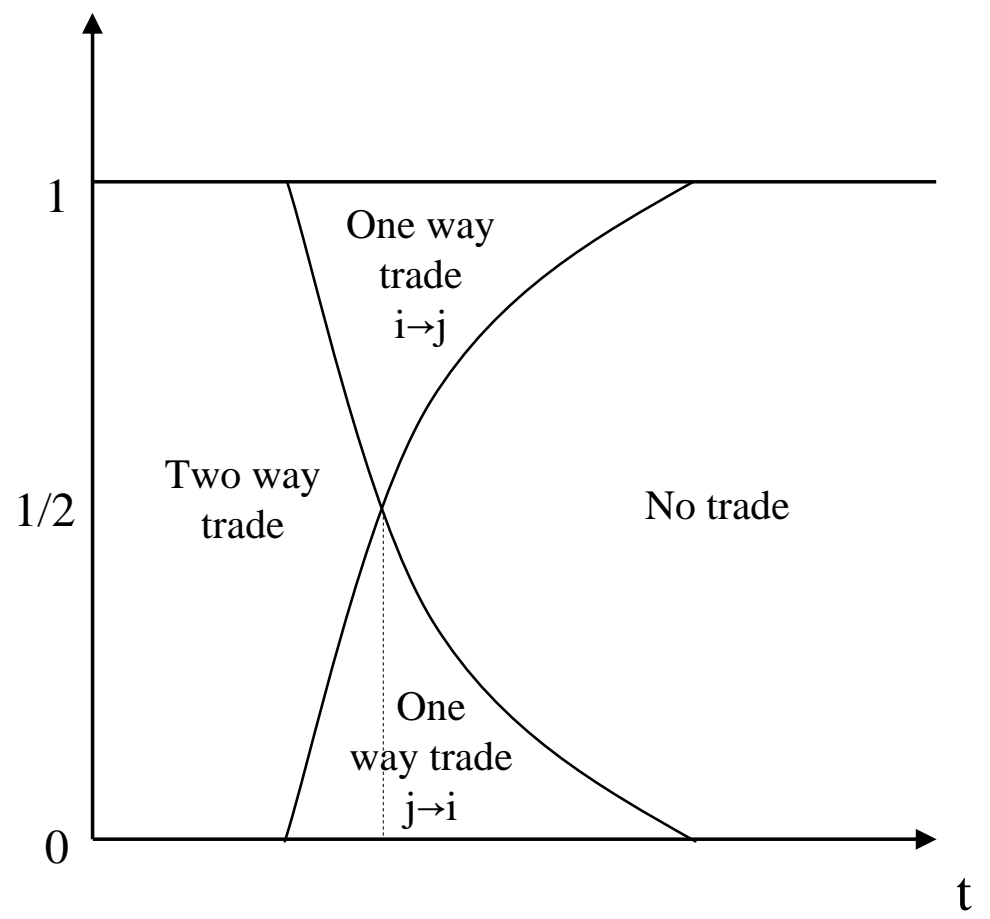

Figure 1: Structure of trade in the short run 


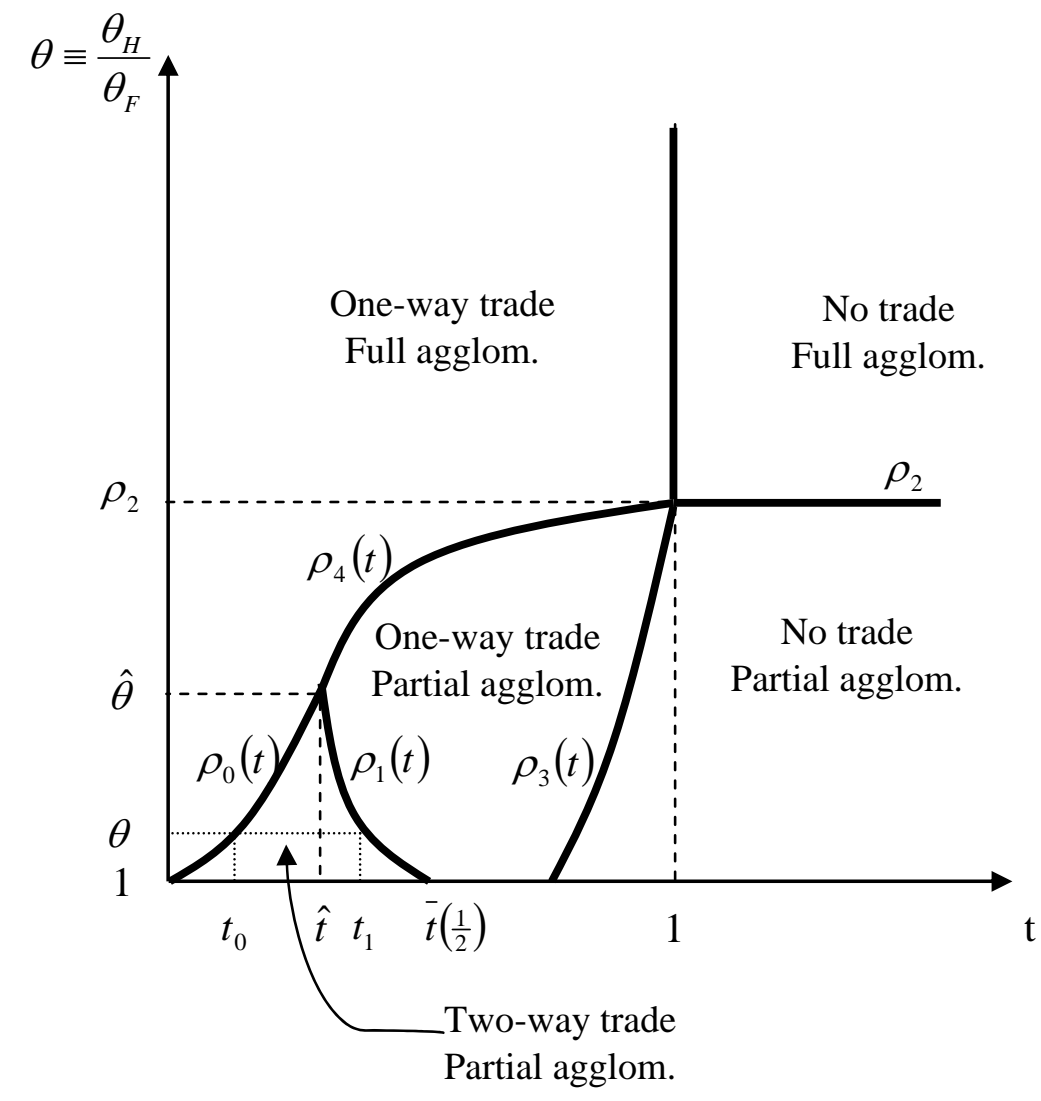

Figure 2 : Structure of trade in the long run 


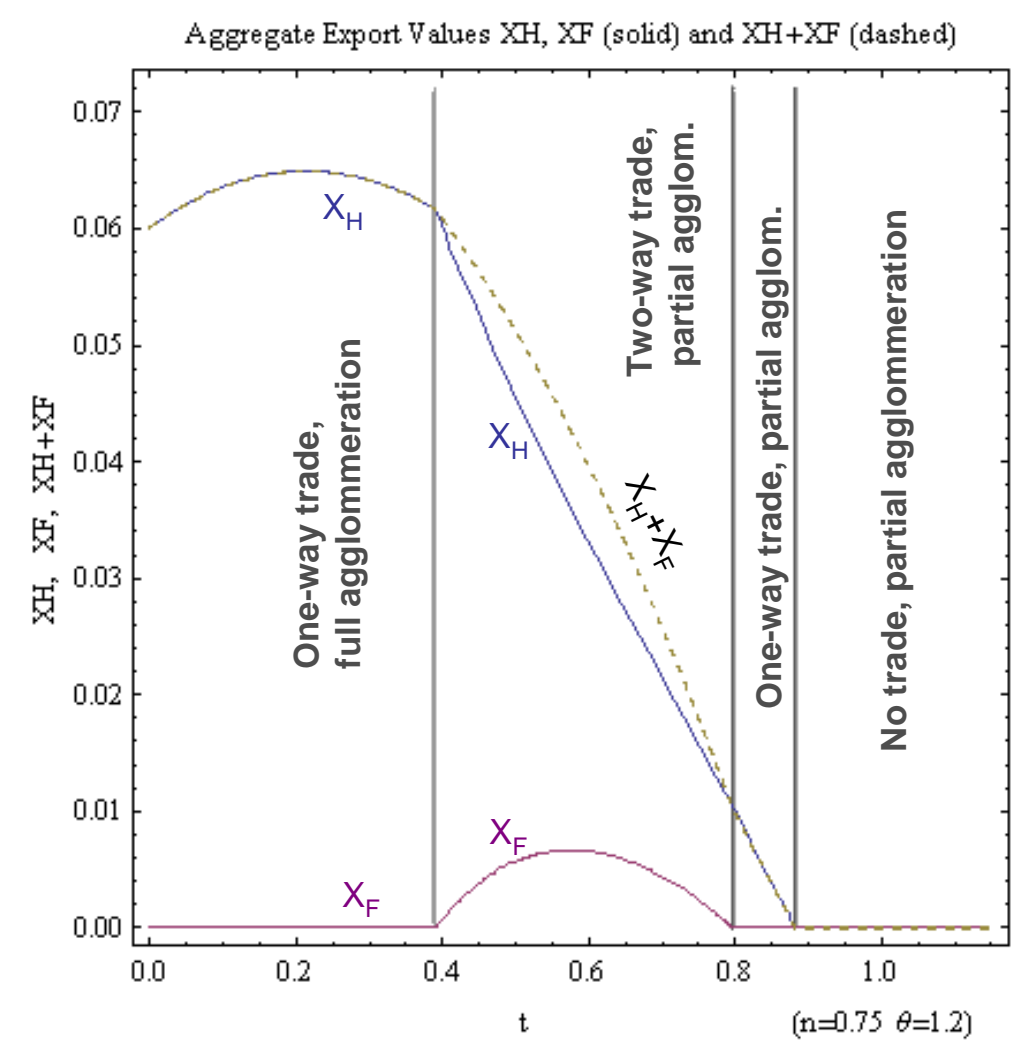

Figure 3 : Aggregate export values as function of trade costs ( $\mathrm{t}$ ) 

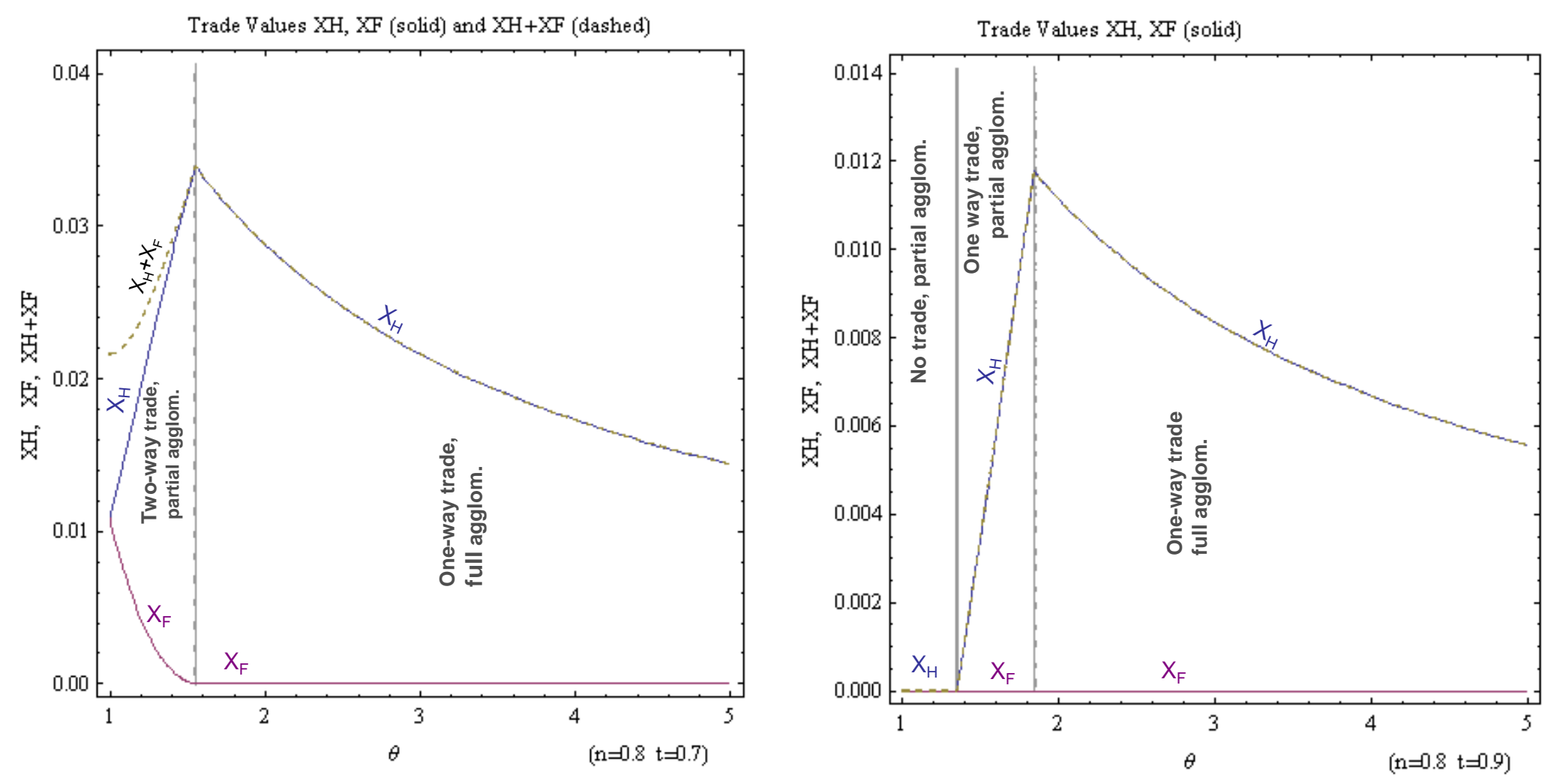

Figure 4: Aggregate export values as function of country size ratio $(\theta)$ 